\title{
IMPLEMENTASI TAHAP KREATIVITAS DAVID CAMPBELL PADA GRUP MUSIK RIAU RHYTHM CHAMBERS INDONESIA
}

\author{
Sutra Laila ${ }^{\text {* }}$, Ardipal ${ }^{2 *}$ \\ Program Studi Pendidikan Ilmu Pengetahuan Sosial Konsentrasi Pendidikan Seni dan Budaya \\ Program Pascasarjana \\ Universitas Negeri Padang \\ Jl.Prof. Dr. Hamta, Air Tawar Padang, Kel. Air Tawar Barat, Kec. Padang Utara, Kota Padang, Kode Pos 25171 \\ Sumatera Barat. Indonesia \\ Email: sutralayla95@gmail.com,ardipalarly@ymail.com
}

\begin{abstract}
Abstrak
Penelitian ini merumuskan tentang implementasi proses kreatif yang dilakukan oleh Riau Rhythm Chambers Indonesia yaitu sebuah grup music yang berasal dari kota Pekanbaru, Riau. Kelompok ini didirikan oleh seorang seniman Riau bernama Rino Deza Paty yang peduliterhadap perkembangan dan kemajuan music Melayu di provinsi Riau. Rino Deza Paty pun tergerak dan mendirikan sebuah kelompok music untuk mengangkat marwah music Melayu khususnya di kota Pekanbaru. Dengan menjadikan music Melayu sebagai konsep utama, RRCI konsisten sebagai kelompok music yang bermain di wilayah-wilayah tradisi kesenian local dan memadukannya dengan music Barat sesuai dengan perkembangan zaman. Proses kreatif ini dianalis is dengan mengacu pada tahap kre ativitas yang diungkapkan oleh David Campbell, dan dengan menggunakan duabuah kary a komposisi yaitu Satellite of Zapin dan lagu Kebangkitan Melayu sebagai media untuk menganalis is hasil dari bentuk kretivitas yang dilakukan dengan menggunakan teori musikologi.
\end{abstract}

Kata Kunci: implementasi, kreativitas, grup musik.

\begin{abstract}
This research formulates the creativeprocess done by Riau Rhythm Chambers Indonesia is a musicgroup originating from the city of Pek anbaru, Riau. The group was founded by a Riau artist named Rino Deza Paty who cares about the development and progress of Malay music in Riau province. Rino Deza Paty was also moved and established a music group to raise the degree of Malay music especially in the city of Pekanbaru. By making Malay music as the main concept, RRCI is consistent as a group of music playing in local arts traditions and combine it with Western mu sic in accordance with development of the Era. This creative process is analyzed by referring to the level of creativity expressed by Da vid Campbell, and by using two compositions of the Satellite ofZapin and the Kebangkitan Melayu song as a medium to analyse the results of the form of creativity by using musical theories.
\end{abstract}

Keywords: implementation, creativity, music group.. 


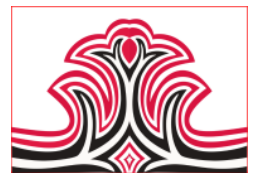

PENDAHULUAN

Indonesia memiliki etnis Melayu yang tersebar di kawasan pesisir pantai Sumatera hingga Kalimantan. Seperti salah satunya etnis Melayu di Provinsi Riaumeskipun terkategori sebagai rumpun ras Melayu, namun memiliki perbedaan dalam hal wujud keseniannya-yang juga memiliki ragam-macam kesenian tradisional yang tumbuh dan berkembang dari masa ke masa.

Terkait persoalan penelitian kesenian tradisional Melayu ini, tidak lain adalah sebagai identifikasi persoalan kesenian tradisional itu sendiri sebagai bahan kajian yang perlu dianalisis dalam wujudnya sebagai bentuk seni yang eksis, khususnya musik dalam konteks tradisional yang kemudian di kemas ulang secara modern sehingga menarik untuk di dengar, dan mampu berdiri sejajar dengan musikmusik industri yang berkembang saat ini.

Sementara dalamhal perkembangan musik Melayu itu sendiri, musik Melayu saat ini telah banyak dikolaborasikan baik dengan berbag ai ins trument nontradisional maupun genre musik lainnya, yang kemudian dikemas dalam suatu kesan menarik untuk di gelar-perdanakan di gedung-gedung pertunjukan maupun diperdengarkan di warung-warung kopi dan tempat-tempat makan, juga ditempat-tempat hiburan. Hal ini merupakan bentuk inovasi yang dilakukan dengan tujuan untuk dapat terus menjaga eksistensi dari kesenian musik Melayu meskipun dalam wujudnyayang baru.

Riau Rhythm Chambers Indonesia (RRCI) adalah salah satu kelompok music yang berdomisili di kota Pekanbaru provinsi Riau. Kelompok ini didirikan oleh seorang seniman Riau bernama Rino Deza Paty yang peduli terhadap perkembangan dan kemajuan music Melayu diprovinsi Riau. Berawal dari fenomena yang terjadi di kota pekanbaru yang pada saat itu seni Tari menjadi bidang kesenian yang selalu mendapatkan perhatian yang lebih terpusat dan positif dalam kehidupan masy arakat Riau.

\section{KAJIAN TEORI}

\section{Kreativitas}

Untuk menganalisis penelitian ini maka penulis memakai teori Kreativitas. David Campbell (1986:11) mengatakan bahwa Kreativitas adalah kegiatan yang
Gorga Jurnal Seni Rupa

Volume 09 Nomor 01 Januari-Juni 2020 p-ISSN: 2301-5942 | e-ISSN: 2580-2380

sifatnya mendatangkan sesuatu yang Baru yang artinya belum ada sebelumnya tetapi menarik dan segar atau sesuatu yang mengejutkan, serta mendatangkan sesuatu yang berguna yang sifatnya lebih praktis dan mempermudah serta membantu dalam pemecahan masalah yang terjadi di dalam lingkungan. Dalam artinya, Kreativitas adalah proses dalam melahirkan sebuah kreasi baru yang berangkat dari penemuan yang sudah ada sebelumnya dengan melalui proses - proses y ang berangkat darifenomena yang terjadi di lingkungan sekitar. Kreativitas itu timbul dengan adanya kegiatan belajar dari pengalaman-pengalaman yang ada sebelumnya, dimana belajar adalah "kemampuan yang dimiliki oleh ses eorang setelah menerima pengalaman belajar yang meliputi mental dan lain sebagainya" (Mesra, 2016:308).

Dalam penelitian ini teori Kreativitas digunakan untuk mengetahui pengaplikasian Kreativitas yang dilakukan oleh RRCI dalam proses penciptaan karya maupun dalam segi bentuk musical dalam karya komposisi yang diciptakan oleh composer RRCI. Untuk melihat proses penciptaan karya komposisi oleh RRCI ini maka digunakan proses Kreativitas menurut David Campbell yang menjelaskan bahwa proses kreativitas memiliki lima tahapan, yaitu tahap Preparation (Persiapan), Concentration (konsentrasi), Incubation (Inkubasi), Illumination (Iluminasi), dan Verification (Verifikasi).

\section{Musikologi}

Teori Musikologijuga digunakan dalampenelitian ini untuk meng analisis atau membedah fenomena musical yang terdapat dalamkary a - karya komposisi $g$ arapan RRCI. Adapun pengertian Komposisi yaitu berasal dari kata Komponieren yang digunakan pujangga jerman yaitu Johann Wolfgang Goethe untuk menandai cara menggubah mus ic pada abad - abad sebelumnya. Karl- Edmund Prier (1996:2) mengemukakan bahwa bentuk music (form) adalah suatu gagasan dalam membuat komposisi yang didalamnya terdapat pengolahan susunan semua unsur music sehingga menjadi satu kesatuan music yang utuh.

\section{METODE PENELITIAN}

Penelitian inimenggunakan penelitian kualitatif untuk merumuskan ulang pengetahuan empiric composer 


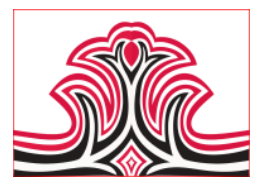

dan para pemain dalam grup music RRCI dalam menggarap karya music berlatar belakang budaya dengan pendekatan analisis Content (Isi).

Analisis Content (Isi) menurut Vredenbreght (1983:66-68) dalam Nyoman Kutha Ratna adalah 'isi’ dalam sebuah komunikasi baik secara lis an maupun tulisan, verbal maupun nonverbal. 'isi' ters ebut bisa meliputi karya seni, karya sastra, arsitektur, pakaian, alat-alat rumah tangga, termasuk media komunikasi mass a seperti film dan televisi. Dalam kajian budaya analis is isi meliputi interaksi social dalam berbagai bentuk. Jadi pada dasarnya analisis isi adalah penelitian yang bersifat pendalaman mendalam terhadap is i suatu informasi.

\section{HASIL DAN PEMBAHASAN}

\section{Hasil}

Dalam penelitian ini yang menjadi sample dalam analis is kreativitas yang dilakukan oleh RRCI adalah komposisi Satellite of Zapin dan lagu Kebangkitan Melayu yang digarap oleh Rino Deza Paty selaku composer dan player dalam grup RRCI. Kedua komposisi ini adalah salah satu single dalam album kedua RRCI yang dirilis pada tahun 2005 dengan komposisi lainnya yaitu; Ragam Budaya, Hoyak Tacobuar, Zapin Kerinduan, Sufi Song, Yung Dolah dan Samba Malay.

\section{1). Tahap Persiapan}

Langkah-langkah dari proses tahapan persiapan dalam penciptaan komposisi musik Satellite of Zapin dan lagu Kebangkitan Melayu dimulai dari (1) Pemunculan Ide, dilakukan dengan memikirkan segala sesuatu yang pernah dialami atau dirasakan, mengunjungi tempat-tempat tertentu secara tidak sengaja maupun sengaja (riset). (2) Materi berupa alat atau instrument, pada komposisi Satellite of Zapin instrument tradisi yang digunakan adalah gambus selodang, tig a buah marwas, gendang bebano, dan darbuka. Pada instrument barat yaitu; biola, accordion, drumset, gitar elektrik, bas s elektrik, flute, clarinet dan keyboard. Sedangkan pada komposisi lagu Kebangkitan Melayu instrument tradisi yang dipilih adalah gambus selodang, gendang bebano dan marwas, dan untuk instrument barat yaitu; biola, accordion, clarinet, drum set, gitar akustik, bass elektrik, piano dan keyboard.
Gorga Jurnal Seni Rupa

Volume 09 Nomor 01 Januari-Juni 2020

p-ISSN: 2301-5942 | e-ISSN: 2580-2380

\section{2). Tahap Konsentrasi}

Pada tahap ini komposer akan memus atkan pikirannya untuk meneruskan penciptaan yang telah dilakukan. Rino mulai menetapkan arah komposisi yang akan dibuat seperti: Struktur Teks Lirik lagu Kebangkitan Melayu:

Rumpun Budaya Negeri Melayu

Kaya Petuah Bijak Bestari

Bersama-sama MariBersatu

Tak kan Melayu Hilang Di Bumi

Refrain: Santun Kata Mari Kita Wujudkan

Kebangkitan Melayu Di NegeriTercinta

Budi Bahasa Seni Dan Budaya

Bangkitlah Melayu Di Negeri Di Bumi Tercinta

Resam Tradisi Bumi Melayu

Kota Bertuah Hai Pekanbaru

Bersama-sama MariBersatu

Tak kan Melayu Hilang Di Bumi

Refrain: Santun Kata Mari Kita Wujudkan

Kebangkitan Melayu Di NegeriTercinta

Budi Bahasa Seni Dan Budaya

BangkitlahMelayu Di NegeriTercinta

Pada bagian refrain kalimat "santun kata" dan kalimat "budi bahasa seni dan budaya" penulis kembali mengajak pendengar untuk tetap menerapkan budi bahasa yang sopan sebagaimana norma-norma yang dilakukan oleh masyarakat melayu, hal ini dilakukan agar budaya dan norma tersebut dapat mempertahankan dan membangkitkan budaya melayu di tempat tanah berpijak yang terdapat pada lirik kebangkitan melayu di negeri tercinta" dan pada kalimat

"bangkitlahmelayudi negeritercinta."

(1). Struktur Musik komposisi Satellite of Zapin, Pada komposisi musik Satellite of Zapin, Rino melakukan pengembangan pada rhythm yang dimainkan oleh perkusi dengan tetap memakai tempo dasar dan mengembangkan ritme dari teknik interlooking dari music zapin. 

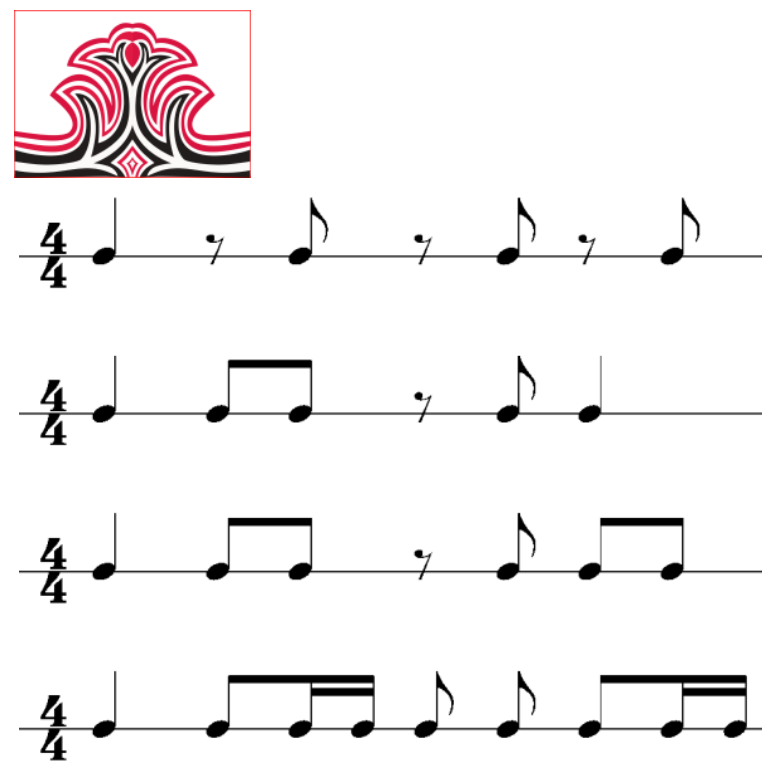

Gambar 1. Notasi 1, Ritme Teknik Dasar Interlude Rentak Zapin

(Sumber: Sutra Laila, 2020)

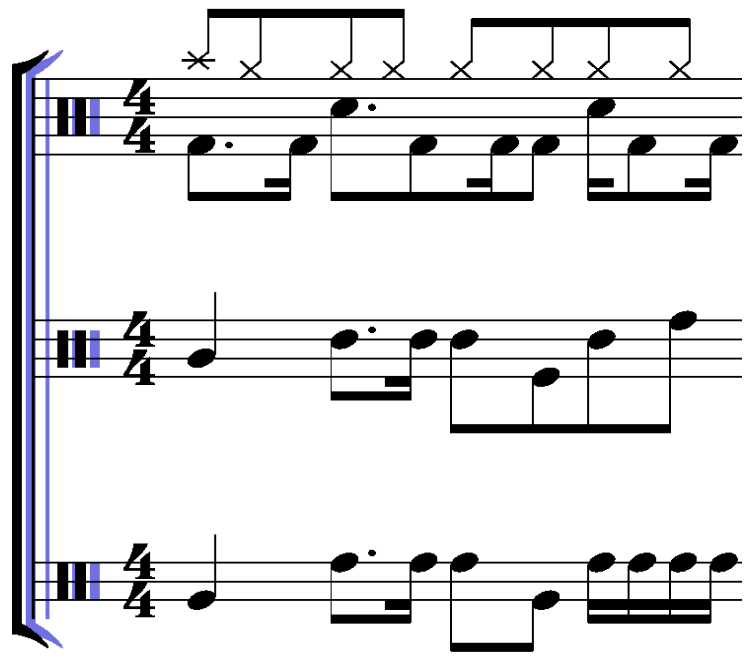

Gambar 2. Notasi 2, Pengembangan Ritme Zapin pada Komposisi Satellite of Zapin

(Sumber: Sutra Laila, 2020)

Secara umum struktur musik Satellite of Zapin merupakan bentuk lagu satu bagian dengan pemakaian tempo $70=$ andante (sedang) dan berubah ke tempo $110=$ allegretto (cepat) memakai nada dasar F Mayor deng an sukat4/4. Ritme melodi kary a Rino Deza Paty ini termasuk komposisi yang sederhana dan easy listening begitu juga dengan bentuk interval melodinya yang dominan dengan teknik notasi interlocking yaitu nada/ritme bersaut-sautan antara dua instrumen atau lebih.
Gorga Jurnal Seni Rupa

Volume 09 Nomor 01 Januari-Juni 2020

p-ISSN: 2301-5942 | e-ISSN: 2580-2380

\section{3). Tahap Inkubasi}

Proses konsentrasi ini dilakukan dengan latihan rutin bers ama dengan pemusik yang lain. Sebagai dampak nyata dari proses latihan yang berkepanjangan, salah satu keuntungan dari konsep karya Rino yang beranting adalah memudahkan dalam proses latihan. Bias anya Rino hanya memberikan clue pada pola yang akan dimainkan.

Rino selaku composer dari grup RRCI selalu memberikan arah dalam proses pemilihan instrument musik. Dari cara memainkan serta variasi yang nantinya akan ditampilkan dipersiapkan pada proses penentuan. Berbagai cara dalam pengkolaborasian penggunaan instrument musik ditentukan oleh Pembina. Hal-hal seperti fungsi alat musik dikolaborasikan dalam proses latihan komposisi musik yang dilakukan RRCI.

\section{4). Tahap Iluminasi}

Tahap ini merupakan tahap penetapan instrumen dalam komposisi Satellite of Zapin yaitu, gambus, klarinet, biola, akordion, gendang bebano, drum set, marwas, bas s elektrik dan gitar elektrik.

Sedangkan pada komposisi kedua instrument yang digunakan adalah gambus selodang, gendang bebano dan marwas, biola, accordion, clarinet, drum set, gitar akustik, bas s elektrik, piano dan keyboard.

\section{5). Tahap Verifikasi}

Dalam hasil dari proses kreativitas terkait grup RRCI dteruskan dalam bentuk penyajian. Dalam penyajiannya, komposisi musik Satellite of Zapin ini mengisyarakatkan adanya beberapa orang sebagai pemain dan diwujudkan melalui bentuk visual penyajian komposisi musik tersebut seperti; formasi, kostum, ekspresi, bahkan juga properti yang disesuaikan dengan komposisi karya.

Pada pemilihan kostum RRCI lebih berkomitmen untuk mencampurkan budaya kostum pertunjukan tradisi dengan kostum pertunjukan barat. Sedangkan pada instrument atau alat music yang digunakan pada komposisi Satellite of Zapin terdiri dari instrument tradisi yaitu, gambus selodang, gendang bebano, dan darbuka. Dan pada instrument barat yaitu klarinet, biola, akordeon, drum set, bass elektrik dan gitar elektrik. 


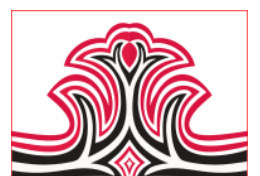

Pada komposisi lagu Kebangkitan Melayu instrument yang digunakan adalah gambus selodang, gendang bebano, dan pada instrument barat adalah biola, accordion, clarinet, drum set, gitar akustik, bass elektrik, piano dan keyboard.

Pada tata panggung seperti letak instrument, cahaya (lighting), dan penggunaan multimedia menjadi pendukung dalampertunjukan yang digelar oleh RRCI yang merupakan standar desain artistik y ang berbeda tergantung pada lokasi pertunjukan (indoor/outdoor). Hal ini menandakan bahwa standar lokasi pertunjukan RRCI lebih terstruktur pada tata letak alat music dari dua jenis instrument yang berbeda.

\section{Pembahas an}

\section{1). Komposisi Satellite of Zapin}

Komposisi Satellite of Zapin merupakan bentuk lagu satu bagian, dimana dalam satu bagian memiliki dua pecahan bagian besar I dan II yang terdiri dari introduksi, transisi, pengembangan dan repetisi. Struktur dalam komposisi Satellite of Zapin tersebut digambarkan dengan skema; I (a dan b), II (a, a' dan a').

\section{(1). Introduksi}

Intro pada komposisi Satellite of Zapin merupakan introduction independent yang terdiri daribagian intro tersendiri. Bagiannya yaitu dengan key signature in $f$ major (1b) dengan tempo maestoso (serasa megah) dan lambat yang digunakan melalui adlibitum melodi pokok serta memakai sukat 4/4.

Frase anteseden terdapat pada birama 1 sampai 8 dengan progress chord vi-V-IV-III dengan half cadens.

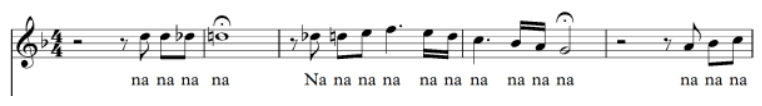

Gambar 3. Notasi 3, Birama 1-8 dengan Progress Chord VI-V-IV-III

(Sumber: Sutra Laila, 2020)

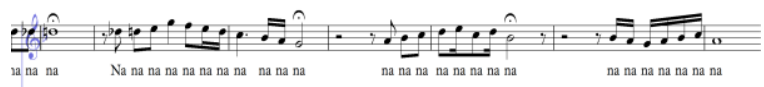

Gambar 4. Notasi 4, Birama 17-24 Motif Ritme Sebelum Masuk Tema Pokok

(Sumber: Sutra Laila, 2020)
Gorga Jurnal Seni Rupa

Volume 09 Nomor 01 Januari-Juni 2020

p-ISSN: 2301-5942 | e-ISSN: 2580-2380

\section{(2). Analisis Komposisi Bagian I}

Pada birama 25-28 merupakan bagian I dan(a) dengan frase anteseden dan deceptive cadence yaitu frase yang bias anya diakhiri dengan chord V-VI, atau V menuju harmoni apapun yang tak terduga (leon stein, 2007: 12).

Dimainkan oleh semua ins trument dengan instrument Gambus, Violin, Flute, dan Accordion sebagai pembawa melodi utama yang dimainkan dengan Unisono. Progres chord nya yaitu II-III-ii7-IV dimana tema dari lagu ini dimulai pada birama 25 pada ketukan 3 dan birama ke 26 ketukan 1 dan 2 . Pada birama 29 - 32 terjadi repetisi atau pengulangan dan dengan frase anteseden.

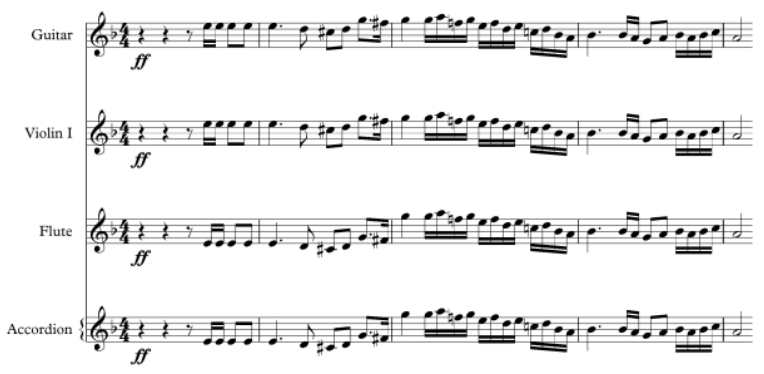

Gambar 5. Notasi 5, Birama 25-28 yang Merupakan Bagian I (Sumber: Sutra Laila, 2020

\section{(3). Analisis Komposisi Bagian II}

Bagian II dimulai dari birama 70, di birama 70 sampai 73 merupakan bagian (a) dengan frase anteseden dan birama 74 sampai 78 fras e kons ekuen yang merupakan repetisi dengan authentic cadence dan proges chord iii-ii-vii-I. Pada birama 70-73 juga terjadi perubahan chord dengan teknik descending (interval akor yang turun) yang digunakan juga pada motive melodi berikutnya dalams atu phraseini.

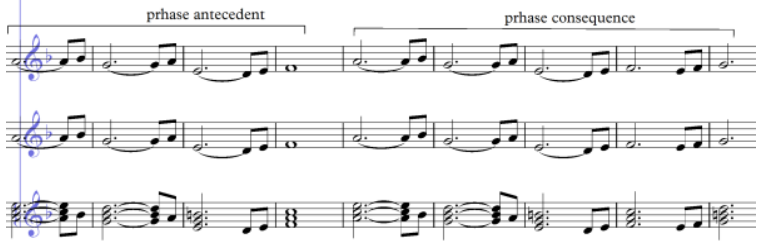

Gambar 6. Notasi 6, Bagian (a) pada Bagian Kedua Birama 70-73 Merupakan Prhase Antecedent Birama 74-78 merupakan Prhase Consequence (Sumber: Sutra Laila, 2020 


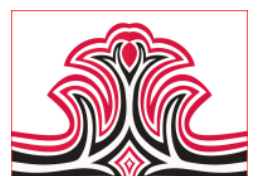

Pada birama 79 sampai 82 merupakan bagian transisi yang meng gunakan penahanan pada proges chord VII, melodi yang digunakana dibagian transisi ini dimainkan oleh violin dan flute dengan Teknik oktaf dan trill.

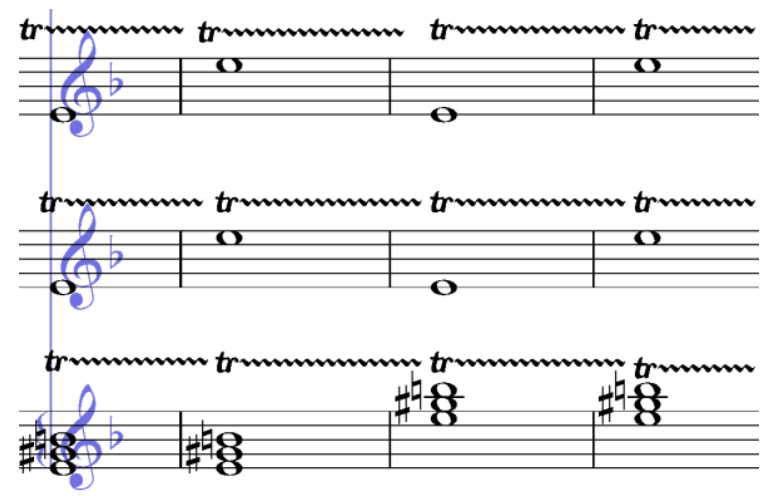

Gambar 7. Notasi 7, Birama 79-82, Bagian Transisi pada Progres Chord VII

(Sumber: Sutra Laila, 2020

\section{2). Komposisi Lagu Kebangkitan Melayu}

Kompos is i lagu Kebangkitan Melayu merupakan lagu dua bagian (part) sederhana deng an jumlah 66 birama pada full score-nya. Dua bagian ini terdiri dari intro, lagu, interlude dan coda. Lagu ini digarap dengan konsep pop melayu secara universal dengan menggunakan instrument band dengan tambahan instrument tradisi.

\section{(1). Introduksi}

Terdapat pada birama 1 sampai 8 yang diawali dengan melodi biola dan akordion yang dimainkan dengan nada dasar E Mayor dengan sukat 4/4 dan dengan tempo Andante $=90$.

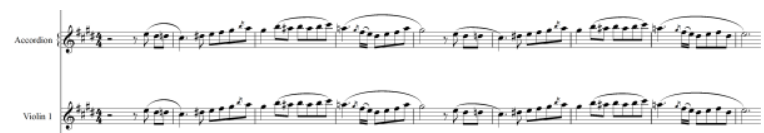

Gambar 8. Notasi 8, Bagian Introduksi pada Komposisi Lagu Kebangkitan Melayu (Sumber: Sutra Laila, 2020)

\section{(2). Bagian I}

Bagian I terdapat pada birama 9 sampai 16 yang merupakan Periode pararel, yaitu alur melodi frase konsekuen yang mirip dengan alur melodi frase pertamanya (Leon Stein, 2007: 49). Disebut dengan parallel period dikarenakan bagian I merupakan verse
Gorga Jurnal Seni Rupa

Volume 09 Nomor 01 Januari-Juni 2020

p-ISSN: 2301-5942 | e-ISSN: 2580-2380

(lagu 1) yang diulang (ke lagu 2) dengan lirik yang berbeda.

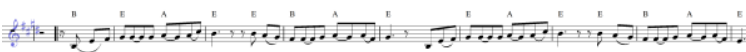

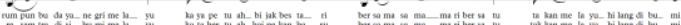

Gambar 9. Notasi 9, pada Verse Lagu 1 dan Diulang ke Lagu 2 (Sumber: Sutra Laila, 2020)

Pada birama 9 sampai 12 merupakan frase anteseden dengan plagal kadens y ang diakhiri dengan chord IVI.

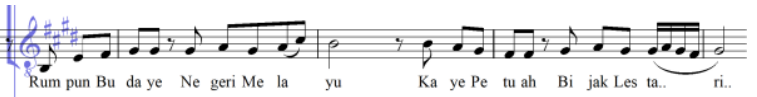

Gambar 10. Notasi 10, Frase Anteseden pada Bagian I (Sumber: Sutra Laila, 2020)

Pada birama 13 sampai 16 merupakan frase konsequen yang juga merupakan plagal kaden karena frase diakhiri dengan chord I.

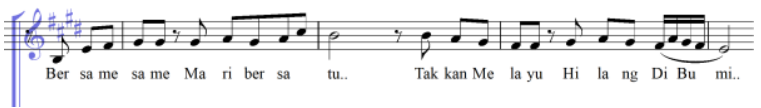

Gambar 11. Notasi 11, Frase Konsequen pada Bagian I (Sumber: Sutra Laila, 2020)

\section{(3). Bagian II}

Birama 17 hing ga 25 merupakan bagian II yang juga merupakan jenis parallel period. Birama 17 sampai 20 merupakan frase anteseden dengan kadens Imperfect Authentic Cadence.

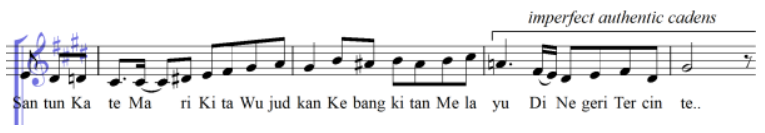

Gambar 12. Notasi 12, Frase Anteseden pada Birama 17 sampai 20

(Sumber: Sutra Laila, 2020)

Sedangkan pada frase konsekuen terdapat padabirama 21 sampai 25 dengan kadens authentic cadence dan progress chord I-IV-V-I. 


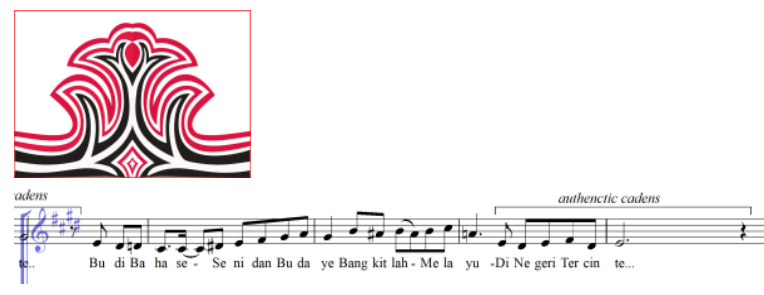

Gambar 13. Notasi 13, Frase Konsekuen pada Birama 21 sampai 25

(Sumber: Sutra Laila, 2020)

\section{KESIMPULAN DAN SARAN}

\section{Kesimpulan}

Kreativitas yang timbul datang dari berbagai kemungkinan namun biasanya ide itu berlangsung dengan hadirnya suatu keterampilan, keahlian, atau ilmu pengetahuan tertentu sebagai latar belakang atau sumber dari mana ide itu lahir. Termasuk juga dalam penentuan instrument yang akan digunakan, sampai kepada sasaran konsumen. Proses kreativitas juga muncul apabila composer memusatkan pikiran ke dalam penciptaan yang akan dilakukan seperti bagaimana menafsirkan isi dari lagu (struktur teks, diksi, pengimajinasian, tema dan konsep) dan penetapan struktur komposisi.

\section{Saran}

Perlunya kajian ilmiah yang mendalam baik secara seminar maupun workshop bagi para akademisi seni pertunjukan agar dapat mengembangkanunsur - unsur pada masing - masing proses kreatif secara lebih mendalam. Sehinggadapat memperkaya keilmuan dan pengetahuan masyarakat modern terhadap music tradisional Melayu dan bagaimana cara pelestariannya.

\section{DAFTAR RUJUKAN}

David, Campbell. (1986). Mengembangkan Kreativitas. Yogyakarta: Kanisius.

Karl-Edmund, Prier. (1996). Ilmu Bentuk Musik. Yogyakarta: Pus at Musik Liturgi.

Leon, Stein.(1979). Structure \& Style, The Study And Analysis of Musical Forms. New Jersey: Summy-Birchard Music.

Mesra, M., Azis, A. C. K., \& Astuti, W. W. (2016). Kontribusi Motiv asi Belajar Dan Lingkungan Tempat Tinggal Terhadap Hasil Belajar Mahasis wa Jurusan Seni Rupa Universitas Negeri Medan. Jurnal Bahas Unimed, 27(3), 302-319.

Nyoman, Kutha Ratna. (2010). Metodologi Penelitian, Kajian Budaya dan Ilmu Sosial Humaniora 